\title{
THE GRUCA OPERATION FOR CONGENITAL ABSENCE OF THE FIBULA
}

\author{
I. H. THOMAS, P. F. WILLIAMS
}

\author{
From the Royal Children's Hospital, Melbourne
}

\begin{abstract}
An alternative to Syme's amputation for congenital absence of the fibula is described in this paper. Nine children have had the ankle reconstructed using the Gruca technique with a very satisfactory result in eight. This procedure is not suitable for every patient and in most unilateral cases the operation can only be regarded as an interim procedure because of progressive leg-length inequality. The decision to remove the foot may be delayed and it allows childhood to be spent without resort to prostheses. However, the procedure can be considered as the definitive operation in cases of bilateral deformity.
\end{abstract}

The syndrome of congenital absence of the fibula consists of complete or partial absence of the fibula, anteromedial tibial bowing with shortening of the tibia and fixed equinovalgus of the foot. The foot is often small in length, height and width. Associated abnormalities include tarsal coalition, absent tarsal bones and rays and, in some, the development of a ball-and-socket ankle joint. The classification proposed by Coventry and Johnson in 1952 (Table I) and subsequently refined by Achterman and Kalamchi (1979) paved the way for a rational approach to the management of this condition.

A conservative plan of treatment is feasible in the mildest forms where the final shortening is not expected to be greater than $7.5 \mathrm{~cm}$. For the severe type, presenting at birth with marked dysplasia of the foot and shortening which would inevitably progress to gross leg-length inequality, an early Syme's amputation is the logical choice (Kruger and Talbott 1961; Westin, Sakai and Wood 1976). Between these two extremes there are cases in which the outcome cannot be accurately predicted. Such children may have little shortening of the tibia at birth and little increase during the early years. Under these circumstances there is an obvious advantage in saving the foot and this is equally true if the condition is bilateral or the other limb is absent.

Over the years many attempts have been made to correct the deformity and to achieve stability at the

I. H. Thomas, MD, FRCS Ed, Clinical Research Fellow

P. F. Williams, AO, FRCS, FRACS, Senior Orthopaedic Surgeon

The Royal Children's Hospital, Flemington Road, Parkville, Victoria 3052, Australia.

Requests for reprints should be sent to Mr P. F. Williams. (C) 1987 British Editorial Society of Bone and Joint Surgery $0301-620 \mathrm{X} / 87 / 4115 \$ 2.00$
Table I. Classification of congenital absence of the fibula (Coventry and Johnson 1952)
Type I. Partial unilateral absence of the fibula. Shortening of the extremity.
Minimal or no bowing of the tibia.
Little or no deformity of the foot.
No other congenital abnormalities
Type II. Fibula completely or almost completely absent. Unilateral deformity.
Anterior bowing of the tibia with skin dimple.
Equinovalgus foot.
Foot deformity may include absence of tarsal bones, rays or tarsal coalition.

Type III. Bilateral Type I or II, or Type I or II in association with deformities elsewhere in the body.

ankle. It is possible to correct the deformity at the ankle by excision of the fibular anlage (Thompson, Straub and Arnold 1957), by lengthening the calcaneal and peroneal tendons and by performing a posterolateral release of the joint capsule (Harmon and Fahey 1937), but the absence of the lateral malleolus inevitably causes relapse. Operations to reconstruct the lateral malleolus using free bone grafts have been tried (Ashhurst 1916; Albee 1919), but if performed before the completion of growth the transplanted bone fails to grow and the deformity recurs. The earliest attempt to recreate an ankle mortise by splitting the distal tibia and epiphysis was performed by Bardenhauer in the nineteenth century. Subsequently Serafin (1967) described the operation that Gruca had designed to reconstruct the ankle; the technique is as follows.

Through an anterior approach a long oblique osteotomy of the tibia is carried out (Fig. 1), beginning from a point situated between the lateral and middle thirds of the articular surface of the distal tibial epiphysis and extended proximally and medially. When this osteotomy is opened from the front it is possible to 




Fig. 1

The Gruca procedure. Left, site of the osteotomy through the distal tibia and epiphysis. Right, the medial fragment displaced upwards and the gap filled with a cortical bone graft. (Redrawn from Serafin 1967.)

displace the large medial fragment upwards for about $1.5 \mathrm{~cm}$ and outwards. The talus is now provided with a supporting lateral buttress and the position is maintained by two screws or Kirschner wires and a small cortical graft. The limb is immobilised for three to four weeks by which time union is usually sound and weight-bearing can be allowed.

This paper describes our experience with this procedure in a selected group of patients.

\section{MATERIAL AND METHOD}

Between 1972 and 1983 nine patients had a Gruca ankle reconstruction at the Royal Children's Hospital, Melbourne. Seven patients had unilateral absence of the fibula (Coventry and Johnson 1952: Type II). Two patients had a Type III deformity: one had bilateral absence of the fibula and in the other the contralateral leg was missing. Patients were not considered for the operation if there was considerable shortening at birth, or if the ankle and foot were grossly deformed and the parents preferred amputation. The prerequisite for surgery in the unilateral cases was minimal shortening of the tibia with a foot that comfortably reached the ground. The median age at operation was 15 months (range 8 to 93 months) and the median age at follow-up 7 years (range 3 to 14 years).

Four patients were examined by one of the authors (IHT). The remaining five patients lived too far from the hospital to attend for review and were interviewed by telephone, the parents providing the information where relevant. Details of a recent examination were obtained from a local orthopaedic surgeon who also forwarded clinical photographs and radiographs.

The following details were obtained from the case histories: the initial appearance of the lower leg and foot, additional surgical procedures performed, and the initial and sequential leg-length discrepancy measurements.

At review information relating to patient acceptance of the procedure, footwear and level of activities was sought. By examination, ankle stability, range of movement at the ankle and the appearance of the foot were assessed. A stable ankle was defined as hindfoot valgus of less than $45^{\circ}$ when standing. Anteroposterior and lateral radiographs of the tibia, ankle and foot were obtained and leg-length measurements made by scanogram. For those patients who had had a Syme's amputation these details were elicited from the case histories, clinical photographs and radiographic records made immediately before the amputation.

\section{RESULTS}

Initial appearance of the lower leg and foot. All nine patients had anterior bowing of the tibia, ranging from $5^{\circ}$ to $30^{\circ}$ with a median of $10^{\circ}$, and valgus heels. An equinus deformity was present in three and in one case the foot was also cavus; three feet were plantigrade; and the remaining three feet were pronated, two having the sole of the foot facing laterally.

In two feet there were no tarsal anomalies and all the

Table II. Patients and procedures

\begin{tabular}{lllll}
\hline Patient Sex & Type* & $\begin{array}{l}\text { Age at } \\
\text { operation } \\
\text { (months) }\end{array}$ \\
\hline Additional surgical procedures \\
(with age)
\end{tabular}

- Coventry and Johnson (1952).

ETA, Elongation of tendo Achillis (calcaneal tendon) 
Table III. Leg-length discrepancy

\begin{tabular}{|c|c|c|c|c|c|c|c|c|c|}
\hline \multirow[b]{3}{*}{ Patient } & \multicolumn{4}{|c|}{ First mescurement } & \multicolumn{4}{|c|}{ Final measurement } & \multirow{3}{*}{$\begin{array}{l}\text { Estimated } \\
\text { mature } \\
\text { discrepanc } \\
\text { (cm) }\end{array}$} \\
\hline & \multicolumn{2}{|c|}{ Age } & \multirow[b]{2}{*}{$(\mathrm{cm})$} & \multirow{2}{*}{$\begin{array}{l}\text { Growth } \\
\text { inhibition } \\
\text { factor* } \\
\text { (per cent) }\end{array}$} & \multicolumn{2}{|l|}{ Age } & \multirow[b]{2}{*}{$(\mathrm{cm})$} & \multirow{2}{*}{$\begin{array}{l}\text { Growth } \\
\text { inhibition } \\
\text { factor* } \\
\text { (per cent) }\end{array}$} & \\
\hline & $(\boldsymbol{y})$ & $(m)$ & & & $(\boldsymbol{y})$ & $(m)$ & & & \\
\hline 1 & 1 & 0 & 4.5 & 23 & 8 & 3 & 8.0 & 23 & 12.0 \\
\hline 2 & 0 & 2 & 1.0 & 12 & 10 & 9 & 9.0 & 17 & 14.0 \\
\hline 3 & 0 & 1 & 1.5 & 33 & 3 & 7 & 5.5 & 31 & 19.5 \\
\hline 4 & 0 & 1 & 1.0 & 20 & 10 & 4 & 7.0 & $20(29) \dagger$ & 13.5 \\
\hline 5 & 0 & 2 & 1.5 & 20 & 6 & 6 & 8.0 & 25 & 16.0 \\
\hline 6 & 0 & 1 & 3.0 & 19 & 8 & 4 & 8.5 & 30 & 13.0 \\
\hline 7 & 0 & 1 & 2.0 & 34 & 3 & 4 & 5.5 & 33 & 19.5 \\
\hline
\end{tabular}

* Growth inhibition factor is the difference in tibial length compared to the contralateral tibia † Calculated prior to contralateral tibial shortening

rays were present. In four feet the lateral ray only was absent, in two the fourth and fifth rays were missing and one foot had two tarsal bones and a single ray.

Additional surgical procedures (Table II). The fibular anlage was excised in only one patient (Patient 8). She was the first patient in the series and had no contralateral leg. After a rapid release of the valgus deformity the ankle was reconstructed; this is still functioning satisfactorily 14 years later.

The calcaneal tendon was lengthened and posterolateral capsular release performed on one patient before the Gruca procedure and on three patients afterwards. Two of these four patients were born with an equinus deformity and two developed one. One patient also had a lateral tarsal release to correct a midtarsal abduction deformity.

Table IV. Condition of the feet at review

\begin{tabular}{|c|c|c|c|c|c|}
\hline \multirow[b]{3}{*}{ Patient } & \multicolumn{4}{|l|}{ Ankle } & \multirow[b]{3}{*}{ Foot } \\
\hline & \multirow[b]{2}{*}{ Stable } & \multicolumn{2}{|c|}{ Range of movement (degrees) } & \multirow{2}{*}{$\begin{array}{l}\text { Heel } \\
\text { valgus } \\
\text { (degrees) }\end{array}$} & \\
\hline & & Dorsiftexion & Plantarilexion & & \\
\hline 1 & + & $\mathbf{0}$ & $5-20$ & 25 & Planus \\
\hline 2 & + & 5 & 40 & 30 & Planus \\
\hline 3 & + & 5 & 15 & 25 & Planus \\
\hline 4 & + & $\mathbf{0}$ & 30 & $\mathbf{0}$ & Normal \\
\hline $5^{*}$ & + & $\mathbf{0}$ & 30 & 25 & Planus \\
\hline 6* & + & $\mathbf{0}$ & $10-20$ & 15 & Planus \\
\hline $7 *$ & - & $\mathbf{0}$ & 10 & 70 & Pronated \\
\hline 8 & + & 5 & 5 & 45 & Planus \\
\hline 9 & + & 5 & 40 & 20 & Planus \\
\hline
\end{tabular}

* Immediately prior to Syme's amputation
Three patients developed an unacceptable leglength discrepancy and have since had a Syme's amputation. The patient with bilateral absence of the fibula (Patient 9) had a contralateral Syme's amputation one month after the Gruca operation. The shortening was considered to be too great and the foot too deformed to warrant ankle reconstruction.

Leg-length discrepancy. The median initial discrepancy was $1.5 \mathrm{~cm}$ with a range of 1.1 to $4.5 \mathrm{~cm}$. This measurement included shortening in both the tibia and femur although the contribution of the latter was in all cases minimal and less than $5 \%$. The difference in tibial length in the unilateral cases was expressed as a proportion of the length of the unaffected tibia (Table III). This is known as the growth inhibition factor (Green and Anderson 1960) and the median was 20\% (range $12 \%$ to $34 \%$ ). Comparison with the growth inhibition factors calculated from the final measurements shows that in three cases (Patients 1, 3 and 7) the growth inhibition remained constant following the Gruca procedure, in two there was a $5 \%$ increase (Patients 2 and 5) and in two the increase was of the order of $10 \%$ (Patients 4 and 6). The estimated mature discrepancy was calculated for the group including what it would have been for the three patients $(5,6$ and 7$)$ who had already had a Syme's amputation.

Condition of the feet at review. With the exception of one patient (7) all the feet were plantigrade. Seven out of the nine feet were planovalgus and one was normal (Table IV). Eight ankles were stable; the only patient with an unstable ankle walked on his medial malleolus and had a Syme's amputation at the age of three years. Two patients ( 1 and 6$)$ had hindfoot equinus, three had no ankle dorsiflexion beyond neutral (Patients 4, 5 and 7) and the remaining four (Patients 2, 3, 8 and 9) had limited dorsiflexion. The median range of plantarflexion was $20^{\circ}$. Excluding the unstable ankle, the median 


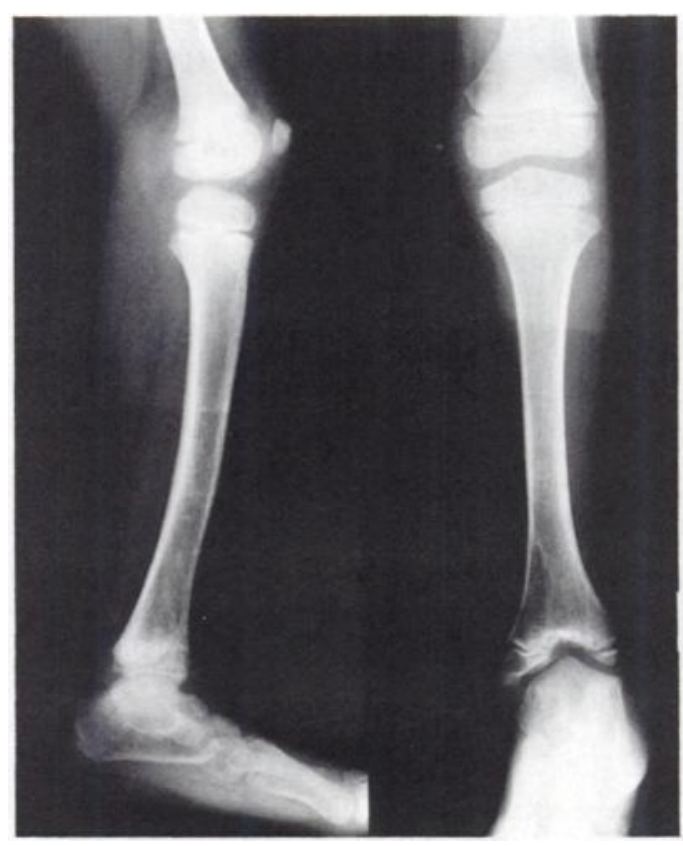

Fig. 2

Patient 1. Lateral and anteroposterior radiograph of left leg seven years after the Gruca procedure.



Fig. 3

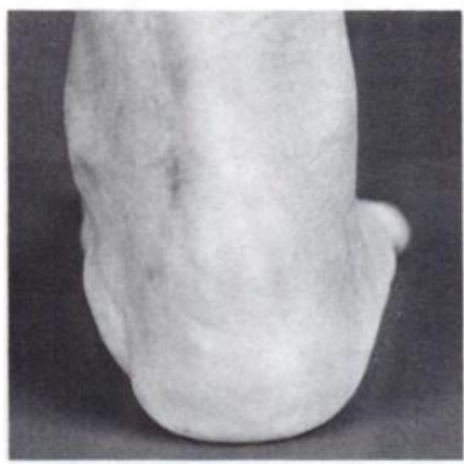

Fig. 4

Patient 4. Figure 3 - Posterior view of the legs in Patient 4 two years after the Gruca procedure showing the valgus heel and shortening of $5 \mathrm{~cm}$. Figure 4 - Posterior view of the ankle and foot at review showing the neutral heel. Figure 5-Anterior view of the legs at review (nine years after the Gruca operation and two years after the contralateral tibial shortening) showing a satisfactory foot and shortening of $7 \mathrm{~cm}$. Figure 6 - Lateral and anteroposterior radiograph of right leg nine years after the Gruca procedure.



Fig. 5



Fig. 6 
hindfoot valgus angulation was $25^{\circ}$ (range $0^{\circ}$ to $45^{\circ}$ ). The three patients who had a Syme's amputation had excellent stumps on which they could bear weight and used standard Syme's prostheses.

There were no significant problems with fitting footwear. Six patients wore boots with a raise. One patient (1) used an ankle-foot orthosis and another (Patient 9) a heel cup for comfort even though the ankle was considered to be stable. The three girls wore normal shoes, two with a raise.

Radiographic review. Measurement of the degree of anterior tibial bowing at review demonstrated that the bowing had not increased with the passage of time in any of the legs. The median angle was $10^{\circ}$ (range $0^{\circ}$ to $25^{\circ}$ ). The bowing had improved in five patients, three of whom had straight tibiae.

A review of the radiographs revealed marked similarities in the appearance of the reconstructed ankle joints. A common feature was a broad distal tibia shaped like an inverted $Y$ (Fig. 2). During growth there were two epiphyseal ossific centres, one on either side. The growth of the lateral epiphysis often lagged behind that on the medial aspect and this contributed to the valgus tilt of the talus. The tent-like appearance of the distal tibia increased in height due to closure of the central part of the physis. The appearance bore some resemblance to the aftermath of a Salter-Harris Type IV fracture which is in effect what occurs during the Gruca operation. There was a good joint space and the dome of the talus had adapted to the change in shape of the distal tibia, maintaining congruity. There was one exception to the general pattern: in Patient 4 the final radiograph showed a flat tibial plafond parallel to the floor. At the age of 10 years the medial physis was closing and the lateral one had already closed leaving a shortened lateral buttress. The flattened dome of the talus had been noticed five years previously when a posterior release was performed. This ankle with a neutral heel in association with a nearnormal foot was functionally and cosmetically the best in the series (Figs 3 to 6).

Patient acceptance and level of activities. Without exception all the patients and their parents were pleased with the result of the operation. It is important to note that when the parents bring their infant to the first consultation the majority do not want to hear about amputation and readily accept an alternative. The general attitude is summarised by the mother of Patient 6 who wrote one year after the Syme's amputation had been performed: "We were glad we left it (her foot) on until she was eight when the raise could not go any higher without calipers etc. She could get around bare footed which she did quite often at home so she has really had the best of both worlds". In the end it is often the patient not the parents who request amputation as was the case with this patient.

All the patients were normally active during childhood with no specific restrictions except that they may be unable to compete at sport at an equal level with their peers. The exception was Patient 9 whose general level of activity was restricted by her contralateral Canadian hip disarticulation prosthesis. Her walking distance was one kilometre and she played no games.

\section{DISCUSSION}

In the majority of cases of congenital absence of the fibula, growth of the child leads to progressive shortening of the limb. The principal clinical problem in prognosis is not the state of the foot so much as the degree of shortening, which will determine whether the foot will be retained or have to be removed. Kruger and Talbott (1961) suggested that the more normal the foot the greater the eventual shortening but a contrary opinion was given by Hootnick et al. (1977). In this study we were unable to establish any correlation between the extent of the deformity and the amount of shortening. There is now, however, good evidence that the most reliable indicator of final shortening is the initial leg-length discrepancy (Westin et al. 1976; Hootnick et al. 1977).

The most important question is: does the Gruca operation itself make the leg-length discrepancy worse? The technique produces an immediate $1.5 \mathrm{~cm}$ of shortening when the medial fragment is displaced upwards. The long-term effect on tibial growth is shown qualitatively by radiography and quantitatively by the growth inhibition factor. Our values for the initial measurements were very similar to those reported by Westin et al. (1976) who stated that the growth inhibition factor remained remarkably constant during growth, varying by only $5 \%$, which was true for five out of seven cases in our study; however, in two patients it increased by $10 \%$. The radiographic appearances suggest that there is retardation of growth in the distal tibia as one would expect after such an insult to the physis. It may be possible in future to minimise the effect of the operation on growth by inserting a fat graft between the displaced portions of the physis. Normally the contribution to total leg-length by the distal tibia is relatively small but this may become important when there is already significant shortening. Our estimate of the leg-length discrepancy at maturity indicated that these patients would have an unmanageable amount of shortening. Therefore although the Gruca procedure carries some risk to growth potential of the distal tibia, in practice this does not influence the outcome. Three patients have already had a Syme's amputation, three are approaching amputation and one has embarked on a programme of leg-length equalising procedures.

Current opinion concerning Type II congenital absence of the fibula is that a Syme's amputation should be performed, preferably before school age. Although few complications have been reported (Mazet 1968; Davidson and Bohne 1975) they appear to be more common in patients with dysplastic lower legs. Technical 
errors aside, the main problem is posterior migration of the heel pad which is related in part to the bowing of the tibia. This complication invariably causes difficulties with fitting the prosthesis; these can be overcome but the usual consequence is conversion to a patellar tendonbearing prosthesis which is not as satisfactory as a good stump and Syme prosthesis. The tibial bowing in five of our subjects improved with time, which implies that if amputation of the foot is delayed then problems with posterior migration may diminish. In any case, amputation is technically easier to perform and the results more satisfactory in the older child. Furthermore, the Gruca procedure does not compromise the result of a subsequent Syme's amputation.

This study has shown that in a selected group of patients a very satisfactory ankle may be achieved using the Gruca technique. There are considerable advantages in retaining the foot in childhood, for the child is able to run around barefoot. It allows childhood to be spent without resort to prostheses. This is particularly important in countries where large distances separate centres providing prosthetic services. As increasing leg-length inequality becomes a problem it is often the child or parents who raise the question of amputation. The parents of the three patients in this series who have had the foot removed feel that nothing was lost by delaying the amputation.

In conclusion we propose that the Gruca procedure of ankle reconstruction has a useful place in the management of congenital absence of the fibula in selected cases.

\section{ACK NOWLEDGEMENTS}

I. H. Thomas gratefully acknowledges the support of the Wellcome Trust, London, and the Ethicon Foundation of the Royal College of Surgeons of Edinburgh.

\section{REFERENCES}

Achterman C, Kalamchi A. Congenital deficiency of the fibula. J Bone Joint Surg [Br] 1979;61-B:133-7.

Albee FH. Orthopaedic and reconstruction surgery: industrial and civilian. Philadelphia etc: WB Saunders Company, 1919.

Asthurst APC. Congenital absence of the fibula. Ann Surg 1916;63:378-80.

Coreatry MB, Johnson EW Jr. Congenital absence of the fibula. $J$ Bone Joint Surg [Am] 1952;34-A:941-55.

Davidson WH, Bohne WHO. The Syme amputation in children. J Bone Joint Surg [Am] 1975;57-A :905-9.

Green WT, Anderson M. Skeletal age and the control of bone growth. Am Acad Orthop Surg Instr Course Lect 1960;17:199-217.

Harmon PH, Fahey JJ. The syndrome of congenital absence of the fibula : report of 3 cases with special reference to pathogenesis and treatment. Surg Gynecol Obstet 1937;64:876-87.

Hootnick D, Boyd NA, Fixsen JA, Loyd-Roberts GC. The natural history and management of congenital short tibia with dysplasia or absence of the fibula: a preliminary report. J Bone Joint Surg [Br] 1977;59-B:267-71.

Kruger LM, Talbott RD. Amputation and prosthesis as definitive treatment in congenital absence of the fibula. $J$ Bone Joint Surg [Am] $1961 ; 43-A: 625-42$.

Mazet R Jr. Syme's amputation: a follow-up study of fifty-one adults and thirty-two children. $J$ Bone Joint Surg [Am] $1968 ; 50-A: 1549-63$.

Serafin J. A new operation for congenital absence of the fibula: preliminary report. J Bone Joint Surg [Br] 1967:49-B:59-65.

Thompson TC, Straub LR, Amold WD. Congenital absence of the fibula. J Bone Joint Surg [Am] 1957;39-A:1229-37.

Westin GW, Sakai DN, Wood WL. Congenital longitudinal deficiencies of the fibula: follow-up treatment by Syme amputation. J Bone Joint Surg [Am] 1976;58-A :492-6. 